\title{
Biochemical Characterization of Eupatorium glandulosum Plant Extracts
}

\author{
Shabinabanu S. Nadaf* and Jyoti V. Vastrad \\ Department of Textile and Apparel Designing, College of Community Science, University of \\ Agricultural Sciences, Dharwad - 580 005, Karnataka, India \\ *Corresponding author
}

\begin{tabular}{|c|c|}
\hline & B \\
\hline & \multirow{6}{*}{$\begin{array}{l}\text { The present study was undertaken to identify the phytochemicals present in Eupatorium } \\
\text { glandulosum of leaf, stem, flower and root. The use of natural plant part resources for } \\
\text { applying ecofriendly finish for textiles has opened up new avenues in this area of research. } \\
\text { Eupatorium glandulosum (Ageratina adenophora) belongs to the family Asteraceae } \\
\text { Asteraceae is one of the largest families of vascular plants, distributed over most of the } \\
\text { earth and in almost all habitats and comprises of nearly } 1200 \text { species distributed mainly in } \\
\text { the tropical regions of Americas, Europe, Africa, and Asia. Phenolics possess a wide } \\
\text { spectrum of biochemical activities such as antimicrobial and antibacterial activity. The } \\
\text { different plant parts of Eupatorium glandulosum was prepared using two solvents viz., } 70 \\
\% \text { ethyl alcohol and distilled water. Extracts were characterized qualitatively for the } \\
\text { presence of alkaloids, flavonoids, tannins, saponins, and terpenoids and quantitatively for } \\
\text { its Total Phenolic Content (TPC) was determined by Folin-Ciocalteu reagent assay } \\
\text { method. The yield of Eupatorium glandulosum leaf, stem, flower and root using } 70 \% \\
\text { ethanol solvent was found to be higher than the distilled water. Results of phytochemical } \\
\text { screening revealed the presence of alkaloids in all the plant part extracts Eupatorium } \\
\text { glandulosum. However, flavonoids, tannins, saponins and terpenoids were present in some } \\
\text { plant parts. Irrespective of the solvent Total Phenolic Content (TPC) of the leaf extract was } \\
\text { higher compared to the other plant parts. Hence, such compounds contribute to the } \\
\text { antimicrobial and antioxidant activity and can be used for eco-friendly processing and } \\
\text { finishing of the textile material for functional performance. }\end{array}$} \\
\hline & \\
\hline & \\
\hline Article & \\
\hline & \\
\hline & \\
\hline
\end{tabular}

\section{Introduction}

Phytochemicals are the chemicals produced by various parts of the plants. These bioactive constituents of plants include terpenoids, carotenoids, flavanoids, alkaloids, tannins and glycosides. (Santhi and Sengottuvel, 2016) There are about eight thousand naturally occurring plants containing a wide spectrum of phenolics performing biochemical activities such as antioxidant, antimutagenic, anticarcinogenic as well as ability to modify the gene expression (Marinova et al., 2005).

Ageratina adenophora (Spreng) (Syn. Eupatorium glandulosum) belongs to the Family Asteraceae. Asteraceae is one of the largest families of vascular plants, distributed over a major part of the earth and in almost all habitats. The genus Eupatorium belongs to the 
Eupatorieae, one of the 13 tribes of the Asteraceae, and comprises of nearly 1200 species distributed mainly in the tropical regions of America, Europe, Africa and Asia. Eupatorium glandulosum is commonly called Goat weed or Crofton weed (Balaiyeswarya, 2013)

Eupatorium glandulosum is a perennial herbaceous shrub that may grow to 1 or 2 metres $(3.3$ or $6.6 \mathrm{ft})$ height. It has opposite trowel-shaped serrated leaves that are 6-10 cm (2.4-3.9 in) long by 3-6 cm (1.22.4 in) width. The small compound flowers occur in late spring and summer and are found in clusters at the end of branches.

Each flower head is up to $0.5 \mathrm{~cm}$ in the diameter and creamy white. They are followed by a small brown seed with a white feathery parachute. (Vasanthi and Gopalakrishnan, 2013) few species of Eupatorium are known for them medicinal value and are used in pain life, influenza and inflammation. Eupatorium is a widely grown weed in the Western Ghats of Karnataka. Therefore, the study was carried to characterize phytochemical components of Eupatorium glandulosum.

\section{Materials and Methods}

Samples of Eupatorium glandulosum was collected from the field of University of Agricultural Sciences, Dharwad and the different parts (leaf, stem, flower and root) were segregated for further use.

\section{Chemicals used}

Analytical reagent (AR) grade ammonia, chloroform, ethyl alcohol, hydrochloric acid, sulfuric acid, ferric chloride, sodium hydroxide, sodium chloride, sodium carbonate, lead acetate, and gelatin. sodium nitrite, Folin-Ciocalteu reagent, Dragendorff's reagent, Wagners reagent and Gallic acid.

\section{Preparation of extracts}

Different plant parts of Eupatorium were washed separately and dried at $40 \pm 2^{\circ} \mathrm{C}$ in hot air oven. Powdered in a laboratory blended and stored in a refrigerator. Extraction process was optimized by two solvents viz., $70 \%$ ethyl alcohol and distilled water. Two gram of weighed powder was extracted with $25 \mathrm{ml}$ of each solvent, incubated under agitation at $25^{\circ} \mathrm{C}$ for 3 hrs. Centrifuged at $5000 \mathrm{rpm}$ at $5^{\circ} \mathrm{C}$ for $10 \mathrm{~min}$. the supernatant obtained was separated and residue was re-extracted with fresh $25 \mathrm{ml}$ of solvents, the process was repeated and the supernatants were pooled, and the extract obtained was measured and filtered using Whatman filter paper no. 40 $(125 \mathrm{~mm})$. Extracts were stored under refrigeration and further analysis of phytochemicals took place within a week.

\section{Phytochemical analysis}

The chemical tests described by Ajayi et al., (2011), Raaman (2006), Rahul et al., (2010) and Jyoti et al., (2014) were adopted for qualitative phytochemical screening of Eupatorium plant part extracts for the identification of various chemical constituents like alkaloids, flavonoids, tannins, saponins, and terpenoids, the details of which are listed below:

\section{Test for tannins and phenolic compounds}

Ferric chloride test: One milliliter of extract was separately stirred with $10 \mathrm{~mL}$ of distilled water and then filtered. A few drops of 5 percent $\mathrm{FeCl} 3$ were added to the filtrate. Blueblack or blue-green coloration or precipitation was taken as an indication of the presence of tannins.

Gelatin test: Two milliliters of a 1 percent solution of gelatin containing 10 percent $\mathrm{NaCl}$ was added to $1 \mathrm{~mL}$ of the extract. White 
precipitate indicates the presence of phenolic compounds.

Lead acetate test: Three milliliters of a 10 percent lead acetate solution was added to 1 $\mathrm{mL}$ of extract. Appearance of bulky white precipitate confirms the presence of phenolic compounds.

\section{Test for flavonoids}

Ammonia test: A few drops of a 1 percent $\mathrm{NH} 3$ solution was added to $1 \mathrm{~mL}$ of the extract in a test tube. A yellow coloration was observed for the presence of flavonoids.

Sodium hydroxide test: A few drops of a 20 percent $\mathrm{NaOH}$ solution was added to $1 \mathrm{~mL}$ of extract. When $\mathrm{HCl}$ is added, the yellow color of the extract turns to a colorless solution that indicates the presence of flavonoids.

\section{Test for alkaloids}

Dragendorff test: To $1 \mathrm{~mL}$ of extract, a few drops of Dragendorff's reagent were added. A prominent yellow precipitate indicates a positive test.

Wagner test: A few drops of Wagner's reagent were added by the side of the test tube to $1 \mathrm{~mL}$ of extract. A reddish brown precipitate confirms the test as positive.

\section{Test for saponins}

For the foam test, about $1 \mathrm{~mL}$ of the sample extract was boiled in $20 \mathrm{~mL}$ of distilled water in a water bath and filtered; $10 \mathrm{~mL}$ of the filtrate was mixed with $5 \mathrm{~mL}$ of distilled water and mixed vigorously for 15 minutes to form a stable persistent froth.

The presence of froth after 5 minutes was taken as an indication of the presence of saponins.

\section{Test for terpenoids}

To perform the Salkowski test, $1 \mathrm{~mL}$ of each extract was mixed with $0.5 \mathrm{~mL}$ of chloroform, and $1 \mathrm{~mL}$ of concentrated $\mathrm{H}_{2} \mathrm{SO}_{4}$ was added carefully to form a layer. The reddish brown coloration of the interface showed positive results for the presence of terpenoids.

\section{Quantitative estimation of phenolics}

Total phenolic content (TPC) in the extracts was determined using the Folin-Ciocalteu assay method (Singleton and Rossi 1965) with little modification using gallic acid as the reference standard.

All the solvent extracts were diluted to appropriate volumes and were mixed with 2 $\mathrm{mL}$ of a 10 percent $\mathrm{Na}_{2} \mathrm{CO}_{3}$ solution. The mixture was incubated at room temperature for 3 minutes, and $100 \mathrm{lL}$ of Folin-Ciocalteu reagent was added to the mixture.

The resulting solution was incubated for 90 minutes at room temperature in the dark, and the absorbance was measured at $765 \mathrm{~nm}$ using the Ultraviolet-Visible (UV-Vis) spectrophotometer (Jyoti and Giridhar, 2016).

\section{Results and Discussion}

\section{Yield of extracts}

The yield of ethanol extracts of Eupatorium leaf (43 ml of extract $/ 50 \mathrm{ml}$ of solvent) was found to be higher than the distilled water (41 $\mathrm{ml}$ of extract $/ 50 \mathrm{ml}$ of solvent). Eupatorium flower exhibited higher yield in ethanol solvent $(42 \mathrm{ml}$ of extract $/ 50 \mathrm{ml}$ of solvent) followed by distilled water $(40 \mathrm{ml}$ of extract/50 $\mathrm{ml}$ of solvent) extracts (Fig. 1). On the other hand, $37 \mathrm{ml}$ of yield was found in ethanol extract of the root and the stem extract exhibited 30-35 ml yield of extracts in both the solvents. 
Table.1 Phytochemical screening of Eupatorium glandulosum plant part extracts

\begin{tabular}{|c|c|c|c|c|c|c|c|c|c|}
\hline \multirow{3}{*}{$\begin{array}{l}\text { Phytochemical } \\
\text { group }\end{array}$} & \multirow[t]{3}{*}{ Chemical tests } & \multicolumn{8}{|c|}{ Extracts of Eupatorium glandulosum plant parts } \\
\hline & & \multicolumn{5}{|c|}{ Distilled water } & \multicolumn{3}{|c|}{$70 \%$ ethano } \\
\hline & & Leaf & Stem & Flower & Ro & & Leaf & Stem & Flov \\
\hline \multirow[t]{2}{*}{ Alkaloids } & Dragendorff's & +++ & +++ & +++ & ++ & & ++ & +++ & \\
\hline & Wagners & - & - & - & - & & - & +++ & ++ \\
\hline \multirow[t]{2}{*}{ Flavonoids } & Ammonia & - & - & - & - & & - & +++ & ++ \\
\hline & Sodium hydroxide & - & +++ & - & ++ & -+ & - & ++ & \\
\hline \multirow{3}{*}{$\begin{array}{l}\text { Phenolic } \\
\text { compound and } \\
\text { tannins } \\
\end{array}$} & Ferric chloride & +++ & - & - & - & & +++ & - & +-1 \\
\hline & Gelatin & - & - & - & - & & +++ & +++ & ++ \\
\hline & Lead acetate & +++ & +++ & +++ & ++ & -+ & - & +++ & \\
\hline Saponin & Foam & - & - & +++ & + & - & - & - & \\
\hline Terpenoids & Salkowski & +++ & + & +++ & + & 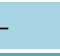 & - & +++ & \\
\hline \multicolumn{10}{|c|}{$\begin{array}{l}(+)=\text { Presence of compound, }(-)=\text { Absence of compound, }(++)=\text { Dark colour and }(+++)=\text { Dark colour } \mathrm{v} \\
\text { precipitate }\end{array}$} \\
\hline \multicolumn{10}{|c|}{$\begin{array}{c}\text { Table.2 Total Phenolic Content (TPC) of different solvent extracts of Eupatorium glandulosum } \\
\text { plant part extracts }\end{array}$} \\
\hline & \multirow[t]{3}{*}{ Solvent extracts } & \multicolumn{8}{|c|}{ Total Phenolic Content mg/g (GAE)* } \\
\hline & & \multicolumn{8}{|c|}{ Eupatorium glandulosum } \\
\hline & & \multicolumn{2}{|c|}{ Leaf } & \multirow{2}{*}{\multicolumn{2}{|c|}{ Stem }} & \multicolumn{2}{|c|}{ Flower } & \multicolumn{2}{|c|}{ Root } \\
\hline & Distilled water/aqueous & \multirow{2}{*}{\multicolumn{2}{|c|}{$\begin{array}{l}55.93( \pm 3.25) \\
70.32( \pm 1.92)\end{array}$}} & & $15.18( \pm 0.13)$ & \multicolumn{2}{|c|}{$48.42( \pm 0.20)$} & \multicolumn{2}{|c|}{$15.12( \pm 0.23)$} \\
\hline \multirow{2}{*}{-} & $70 \%$ Ethanol & & & \multicolumn{2}{|c|}{$15.53( \pm 1.15)$} & \multicolumn{2}{|c|}{$50.39( \pm 0.95)$} & \multicolumn{2}{|c|}{$25.55( \pm 1.74)$} \\
\hline & $=$ Gallic Acid E & & & e de & & & & & \\
\hline
\end{tabular}

Fig.1 Yield of extracts

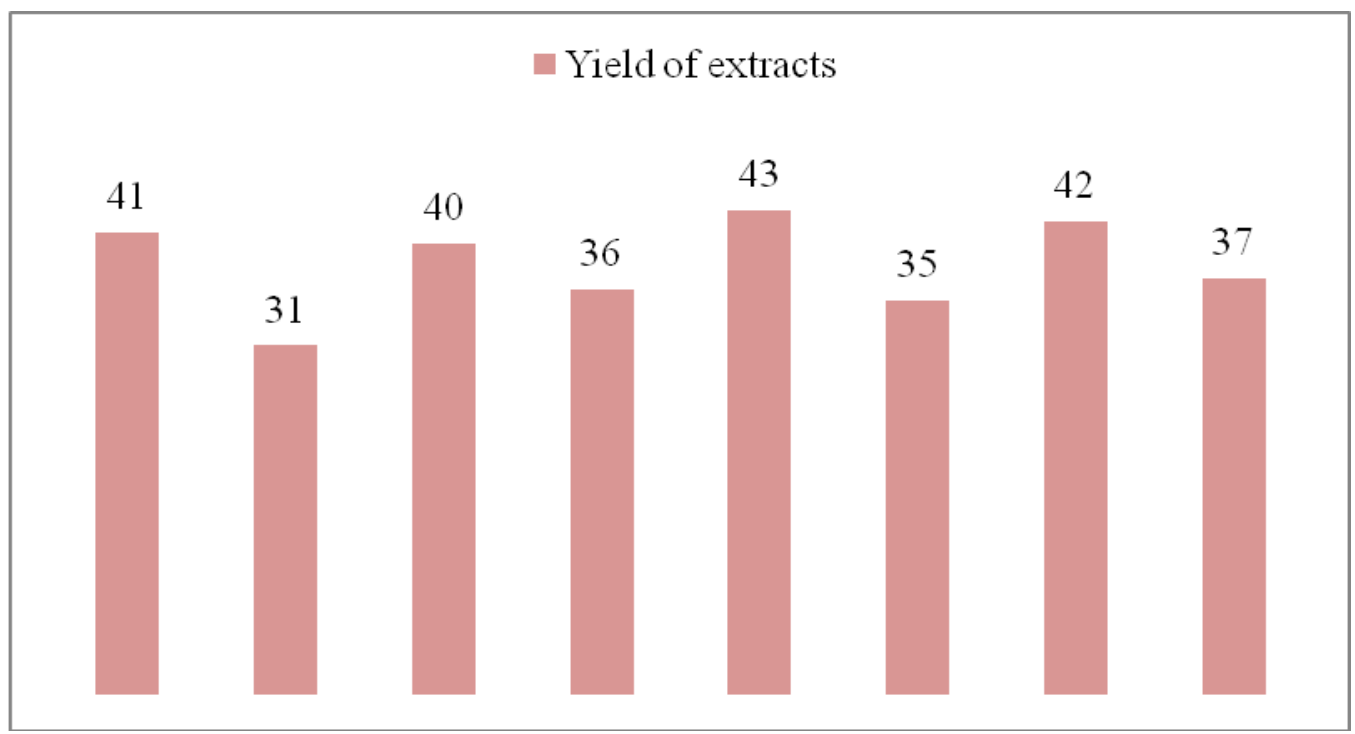


Phytochemical screening of Eupatorium $G$. plant part extracts

Table 1 depicts the results of phytochemical screening of plant extracts of Eupatoriu. From the table it was observed that all the plant part extracts of Eupatorium exhibits positive results for alkaloids as proved by Dragendorff's test in both distilled water and ethanol solvents. In ethanol solvent except leaves all the plant part extracts depicts the positive results for alkaloids by Wagner's test.

The presence of flavonoids was positively proved by ammonia and sodium hydroxide test in ethanol extracts of stem, flower and root of Eupatorium and in aqueous extract of stem and root was positively proved by sodium hydroxide test.

All the extracts of Eupatorium leaf, stem, flower and root indicated the presence of tannins as proven by lead acetate test except in ethanol extract of leaf. Whereas ethanol extract of all the plant parts showed positive results with gelatin test. However aqueous extract of leaf and ethanol extracts of leaf and flower showed the presence of tannins using ferric chloride test.

In both the solvents, flower and root extracts showed the presence of saponins through foam test and no saponins was present in the leaf and stem extracts. In aqueous extract of all the parts of Eupatorium proved the presence of terpenoids with salkowski test and terpenoids was present in ethanol extract of stem and root.

\section{Total phenolic content of different solvent extracts of Eupatorium glandulosum plant part}

Total Phenolic Content (TPC) of solvent extracts of Eupatorium plant part is described in Table 2. In general, TPC was found to be high in ethanol extracts compared to extracts in distilled water, probably due to the affinity of the substances with the employed solvent. Phenolic substances have a higher affinity with polar solvents, such as ethanol and ethyl acetate (Tiwari et al., 2011 and Sideney et al., 2015). Whereas, in both the solvent and total phenolic compound of leaf extracts $(70.32 \mathrm{mg} / \mathrm{g}$ and $50.39 \mathrm{mg} / \mathrm{g}$ ) was found to be high followed by flower and root extracts. On the other hand, ethanol $(50.39 \mathrm{mg} / \mathrm{g})$ extract of Eupatorium flower yielded higher amount of TPC compared to distilled water (48.42 $\mathrm{mg} / \mathrm{g}$ ). Further, Eupatorium stem and root exhibited minimum TPC using aqueous against the phenolic concentration of ethanol solvents.

Alkaloids were found to be present in all the extracts of Eupatorium plant parts. Flavonoids were present in ethanolic extracts of stem, flower and root. All the extracts of Eupatorium leaf, stem, flower and root indicated the presence of tannins as proved by lead acetate test except ethanol extract of leaves. Ethanolic extract of all the plant parts depicted the presence of tannins as proven by gelatin test and only aqueous extract of leaf and ethanol extract of leaf and stem showed the presence of tannins by ferric chloride test.

Positive results for saponins and terpenoids were obtained in all the plant parts of Eupatorium except ethanol extract of leaf and flower. TPC was high in aqueous and ethanol extract of leaf followed by flower, root and stem.

The phenolic components perform varied functions that can be made use of the textile finishing. Eupatorium is a weed and hence the source can be used for eco-friendly processing and finishing of the textile material for functional performance. Studies on the biosafety of utilizing such natural sources also need to be explored. 


\section{References}

Ajayi I A, Ajibade O, and Oderinde R A (2011). Preliminary phytochemical analysis of some plant seeds. Res. J. Chem. Sci. 1:58-62.

Balaiyeswarya, M., Manigundan, K., Usha, J., Suganya Devi, P. and Shanmuga Priya, A., 2013, Phytochemical study of methanolic leaf extract of Eupatorium glandulosum L. BioMedRx., 1(4): 406409.

Jyoti, V, V., and, Giridhar, G., 2016, Evaluation of phenolic compounds and developement of chromatographic profiles in Spathodea campanulata inflorescence by HPTLC. Asian J. of Chemistry, 28(3): 497-500.

Jyoti, V, V., Shameembanu, A, B., Giridhar, G. and Rajashri, K., 2014, Characterization of Phytoconstituents in Leaf Extracts of Forest Species for Textile Applications. Forest Prod. J. 64(7/8): 259.

Marinova. D., Ribarova, F. and Atanassova. M., 2005, Total phenolics and total Flavonoids in Bulgarian fruits and vegetables, Journal of the University of chemical technology and metallurgy, 40 (3): 255-260.

Raaman, N., 2006, Phytochemical Techniques. New India Publishing, New Delhi. pp. 19- 22.

Rahul, C., Pankaj, P., Sarwan, S. K. and Mahesh. J. K., 2010, Phytochemical screening and antimicrobial activity of Albizzia lebbeck. J. Chem. Pharm. Res. 2(5):476-484.

Santhi, K., and Sengottuvel, R., 2016, Qualitative and quantitative phytochemical analysis of Moringa concanensis Nimmo. Int.J.Curr.Microbiol.App.Sci., $\quad 5(1)$ : 633-640.

Sideney Becker Onofre1, Santos Zípora M.Q., Kagimura Francini Y. and Mattiello Shaiana P., 2015, Antioxidant activity, total phenolic and flavonoids contents in Stachytarpheta cayennensis, (Rich.) Vahl. (Verbenaceae), Journal of Medicinal Plants Research, 9(17), 569575.

Singleton, V. L. and Rossi. J. A., 1965, Colorimetry of total phenolics with phosphomolybdic-phosphotungstic acid reagents. Am. J. Enol. Vitic. 16:144158.

Tiwari, P., Kumar B., Kaur M., Kaur, G. and Kaur H., 2011, Phytochemical screening and extraction, A review. Int. Pharm. Sci., 1(1), 98-106

Vasanthi, S. and Gopalakrishnan, V. K., 2013, In vitro antioxidant, antiacetylcholinesterase activity and GCMS analysis of essential oil from flowers of Ageratina adenophora (Spreng). Research Journal of Pharmaceutical, Biological and Chemical Sciences, 4(2): 1419-1428

\section{How to cite this article:}

Shabinabanu S. Nadaf and Jyoti V. Vastrad. 2018. Biochemical Characterization of Eupatorium glandulosum Plant Extracts. Int.J.Curr.Microbiol.App.Sci. 7(04): 2845-2850. doi: https://doi.org/10.20546/ijcmas.2018.704.324 